\title{
Experimental Investigations on the Induced Anisotropy of Mechanical Properties in Polycarbonate Films
}

\author{
Andrea Wibbeke, ${ }^{1}$ Volker Schöeppner, ${ }^{1}$ and Rolf Mahnken ${ }^{2}$ \\ ${ }^{1}$ Department of Polymer Engineering Paderborn (KTP), University of Paderborn, 33098 Paderborn, Germany \\ ${ }^{2}$ Laboratory for Technical Mechanics (LTM), University of Paderborn, 33098 Paderborn, Germany \\ Correspondence should be addressed to Volker Schöeppner; volker.schoeppner@ktp.upb.de
}

Received 22 January 2013; Accepted 13 February 2013

Academic Editors: K. Hokamoto, Y. Kusano, Y. Masuda, and S. Matsuya

Copyright (c) 2013 Andrea Wibbeke et al. This is an open access article distributed under the Creative Commons Attribution License, which permits unrestricted use, distribution, and reproduction in any medium, provided the original work is properly cited.

\begin{abstract}
The prime aim of this paper is to investigate, with the help of experiments, the induced anisotropy of mechanical properties in polycarbonate films. It is known that a molecular orientation in polymer materials occurs through cold-forming. In this study, cold forming is performed at room temperature on a tensile testing machine. The polycarbonate films are examined in two phases. In the first phase, the specimen is loaded, while the prestrain is varied, and in the second, it is loaded, while the material direction is varied. The main findings are that the prestrain has virtually no influence on the anisotropy and that the material direction does exert a major influence. Furthermore, this paper summarizes comparisons of anisotropic characteristic data, maximum stresses, elasticity moduli and failure strain.
\end{abstract}

\section{Introduction}

It is known that the mechanical properties of amorphous polymers are changed by an orientation of the molecular chains. This directional dependence of a material's properties is known as the anisotropy [1]. The effect of orientation concerning the impact strength and the brittle-ductile transition in polycarbonate structure has been studied in [2]. The structure and anisotropy of isotropic and uniaxial drawn samples of polycarbonate studied by WAXS [3] and the elastic and optical properties [4] are also well known. Anisotropy in the hot-formed polycarbonate was investigated already in 1962 by Hofmeier, who studied the tensile strength of amorphous polycarbonate films, produced from bisphenol Abased polycarbonate, and established that the tensile strength can indeed be increased through deformation [5]. During hot forming, the chains are aligned parallel to the direction of the applied force, as a result of which anisotropies are produced in terms of tensile strength, elasticity moduli, and failure strain. In [6], Schultze-Gebhardt examined oriented polycarbonate filaments of bisphenol A polycarbonate. Here, too, a deformation-induced anisotropy was produced through heterogeneous deformation. In the present work, the aim is to analyze the initial anisotropy with regard to the mechanical properties and the deformation-induced anisotropy through cold-forming. The polycarbonate plastic used in the anisotropy tests within this paper is amorphous with an irregular arrangement of the molecular chains (Figure 1(b)). When amorphous thermoplastics cool down, the disorder of the molecular chains remains. In contrast, when the chains of semicrystalline thermoplastics cool down, they arrange themselves in a regular pattern, resulting in crystallization and the formation of ordered states-so-called crystallites (Figure 1(a)). The amorphous state of thermoplastics, on the other hand, does not show any regular orientation of the macromolecules. According to Ehrenstein, closely ordered areas can also occur in amorphous thermoplastics such as polycarbonate [7]. These closely ordered areas (Figure 1(c)) can become orientated through deformation.

The processing of polymer materials leads to the supposition that a morphology with completely isotropic properties virtually never exists. Here, the pressure with which the polymer is molded in the cavity during processing causes a flow. The resultant shear leads to deformation of the coil structure. The molecules deformed in this way solidify in this position as a result of rapid cooling [9]. Flat film extrusion, 


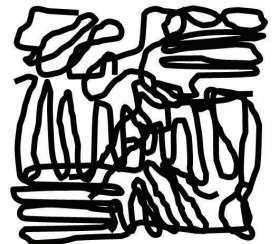

(a)

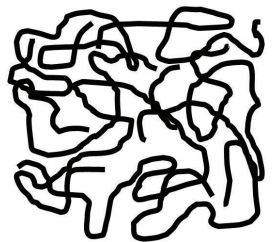

(b)

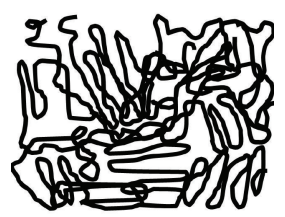

(c)
FIGURE 1: Molecular structures of thermoplastics: (a) a semicrystalline thermoplastic according to [8], (b) an amorphous thermoplastic in line with [8], and (c) closely ordered areas of an amorphous thermoplastic in line with [7].

too, is likely to produce an initial anisotropy in the $x$ and $y$-directions (Figure 2). However, because this is not necessarily desirable for all products, the throughput and takeoff speed are adjusted accordingly. The anisotropy in the $z$-direction is not taken into account here. An already existing initial anisotropy can be increased through a subsequent deformation (stretching), as a result of which a deformationinduced anisotropy can be brought about with directionally dependent material properties. Anisotropic properties in the $x$ - or $y$-direction of the film due to the processing process or as a result of uniaxial stretching can be avoided by biaxial stretching [10]. This process is shown in Figure 2.

In the following investigations, the initial anisotropy of an extruded polycarbonate film will first be examined in the $x$ - and $y$-directions. The deformation-induced anisotropy will subsequently be analyzed by cold-forming on a tensile testing machine and is analyzed in two phases. In the first phase, the films are subjected to a prestrain of differing intensity in order to activate the molecular stretching in the material. The second phase examines the directional dependence of the mechanical properties in relation to the degree of prestraining. With the deformation-induced anisotropy, the directionally dependent stress-strain curve and the relationship between the stress-strain curve and the level of deformation are examined. It is important here to take into account the lateral contraction during the initial stressing, because the cross-sectional area of the specimen changes as a result. From the above studies, we compare anisotropic data, maximum stresses, elasticity moduli, and failure strain.

\section{Definition of Strains and Stresses}

Figure 3 describes, in accordance with [11], the nominal forceelongation curve for an amorphous thermoplastic subjected to a load in the axial direction below the glass transition temperature. The molecule chains orientate themselves in parallel, and the specimen contracts laterally on reaching the

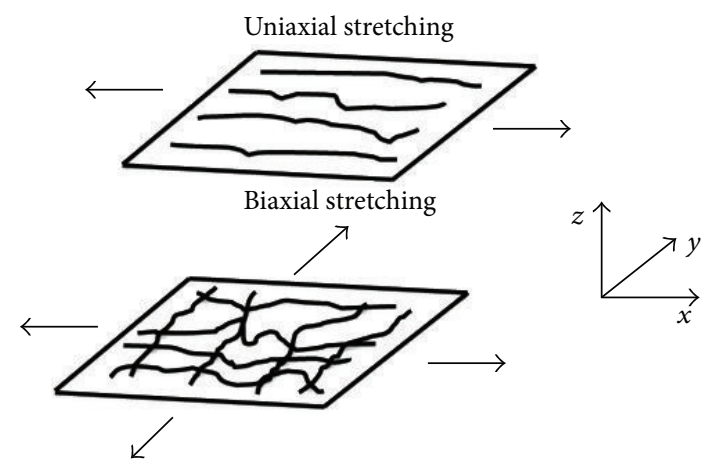

FIGURE 2: Anisotropic/isotropic behavior through uniaxial and biaxial stretching according to [10].

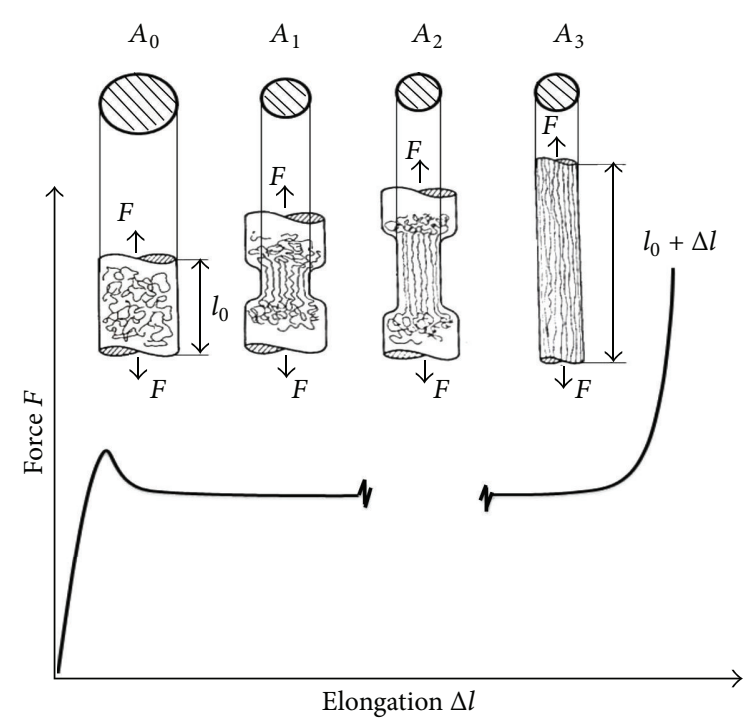

FIgURE 3: Schematic model of the molecular orientation during cold-forming of an amorphous thermoplastic below the glass transition temperature according to [11].

strain limit. As a result, there is a reduction in the crosssectional area so that various stresses and strains are introduced.

The nominal strain $\varepsilon$ is defined as

$$
\varepsilon=\frac{\Delta l}{l_{0}},
$$

where $\Delta l$ is the change in length and $l_{0}$ the length in the original state.

In contrast to the nominal strain $\varepsilon$, the true strain $\varepsilon^{\prime}$ (the Hencky strain) is related to the actual length $l$ of the body, so that the total true strain is defined as

$$
\varepsilon^{\prime}=\ln \left(\frac{l}{l_{0}}\right) .
$$

According to [12], the relationship for small strains between the nominal strain and the true strain is

$$
\varepsilon \cong \varepsilon^{\prime} .
$$


The nominal stress (the 1st Piola-Kirchhoff stress) is defined as

$$
P=\frac{F}{A_{0}}
$$

where $A_{0}$ is the original surface area in Figure 3. This does not change in (4), so that the lateral contraction during the tensile test can be ignored.

The real stress (the Cauchy stress), on the other hand, is defined as

$$
\sigma_{t}=\frac{F}{A_{t}},
$$

where $A_{t}$ is the current area during the tensile test, which means that the lateral contraction is also taken into account. In (5), $A_{t}$ is unknown and can only be stated approximately. The stress can thus be calculated by relating the force $F$ at the beginning of the lateral contraction to the narrowing cross section. On the assumption that the change in the lateral contraction declines with increasing load, then

$$
A_{t} \approx A_{1} \approx A_{2} \approx A_{3} \text {. }
$$

The approximate real stress is therefore calculated in the following experiments with area $A_{3}$ of the final state as

$$
\sigma_{t, n}=\frac{F}{A_{3}} .
$$

Another possibility is to calculate the stress, assuming volume consistency with plastic deformation. Here, the following applies for the volume in the initial state:

$$
V_{0}=l_{0} A_{0}
$$

and, for the volume in the final state, incorporating (1),

$$
V=l A_{t}=\left(l_{0}+\Delta l\right) A_{t}=\left(l_{0}+\varepsilon l_{0}\right) A_{t}=(1+\varepsilon) l_{0} A_{t} .
$$

Neglecting the elastic volume change and assuming plastic incompressibility

$$
V=V_{0} \text {, }
$$

it follows that

$$
A_{t}=\frac{A_{0}}{1+\varepsilon}
$$

The real stress is thus approximated by

$$
\sigma_{\varepsilon}=\frac{F}{A_{t}}=\frac{F}{A_{0}}(1+\varepsilon)=P(1+\varepsilon) .
$$

Here, too, the stress is related to the narrowing cross section with the start of lateral contraction. $A_{0}$ corresponds here to the original surface area $A_{1}$ in Figure 3.

In the following studies, the various stresses are compared to each other. Since the true strain according to (2) merely requires a different scaling than the nominal strain as per (1), the following investigations examine only the nominal strain.

\section{Analysis of the Initial Anisotropy}

Polycarbonate of type Makrolon 2805 was plasticized in a single-screw extruder with a screw length-to-diameter ratio (L/D ratio) of 30 , a barrel wall temperature of $240^{\circ} \mathrm{C}$ to $280^{\circ} \mathrm{C}$, and a screw speed of $45 \mathrm{rpm}$. The material was subsequently extruded through a slit die at $280^{\circ} \mathrm{C}$ with a gap width of $0.5 \mathrm{~mm}$. The film was subsequently drawn off with a chill-roll unit at $4.5 \mathrm{~m} / \mathrm{min}$ and a temperature of $50^{\circ} \mathrm{C}$. After calendering, the film has a thickness of $450 \mu \mathrm{m}$. To determine the initial anisotropy of the mechanical properties, tensile tests are performed on a tensile testing machine 1446 from Zwick AG. The software used for the tests was test Expert II version 3.1. The tensile tests were carried out in line with DIN EN ISO 527-3 [13]. Specimens were taken longitudinally $\left(\alpha=0^{\circ}\right)$ and transversally $\left(\alpha=90^{\circ}\right)$ and elongated until fracture.

Figure 4 shows the different stress-strain curves according to (1), (4), and (12) for $\alpha=0^{\circ}$ and $\alpha=90^{\circ}$. Irrespective of the stress, it is striking that the two curves for $\alpha=0^{\circ}$ and $\alpha=90^{\circ}$ are virtually identical. This means that there is no initial anisotropy. Through the slow takeoff speed $(4.5 \mathrm{~mm} / \mathrm{min})$ in relation to the high screw speed (45 rpm), an isotropic film in terms of its mechanical properties is thus produced. Up to approximately $\varepsilon=5 \%$, the polymer is linearly elastic. Through further deformation, the molecule chains are stretched and align themselves in parallel. The greater the level of stretching, the more the covalent bonds in the molecule are loaded, resulting in local consolidation. This prevents further lateral contraction. Instead, the lateral contraction area along the specimen increases up until $\varepsilon=120 \%$. Above $\varepsilon=120 \%$, the entire specimen consists of stretched, parallel chain molecules. The specimen now becomes deformed through the molecule chains slipping past each other, leading to a visible increase in stress. In Figure 4(a), the force related to the initial area $A_{0}=12.6 \mathrm{~mm}^{2}$ is pictured according to (4). Above $\varepsilon=5 \%$, lateral contraction occurs. Because, in the area of the lateral contraction, the initial area is different, Figure 4(b) shows the approximate real stress-strain profile according to (7). Here, from the beginning of the lateral contraction $(\varepsilon=5 \%)$, the force $F$ is related to the area of the lateral contraction. The lateral contracted area is thus taken constantly as $A_{3}=9 \mathrm{~mm}^{2}$. Here, the maximum stress both for $\alpha=0^{\circ}$ and $\alpha=90^{\circ}$ is approximately $100 \mathrm{~N} / \mathrm{mm}^{2}$. In Figure 4(c), the stress $\sigma_{\varepsilon}$ according to (12) is shown, assuming constant volume. Here, the maximum stress is approximately $180 \mathrm{~N} / \mathrm{mm}^{2}$ and increases with the increasing strain. Because the area of lateral contraction as in (6) does not change any further but merely travels through the specimen, this paper will from now examine only the approximate real stress-strain profile according to (7). Equation (12) will no longer be considered.

\section{Deformation-Induced Anisotropy through Cold-Forming}

To examine the deformation-induced anisotropy, two stress phases are carried out: an initial loading phase in which the prestrain is varied and a subsequent, second loading phase in which the material direction is varied. 


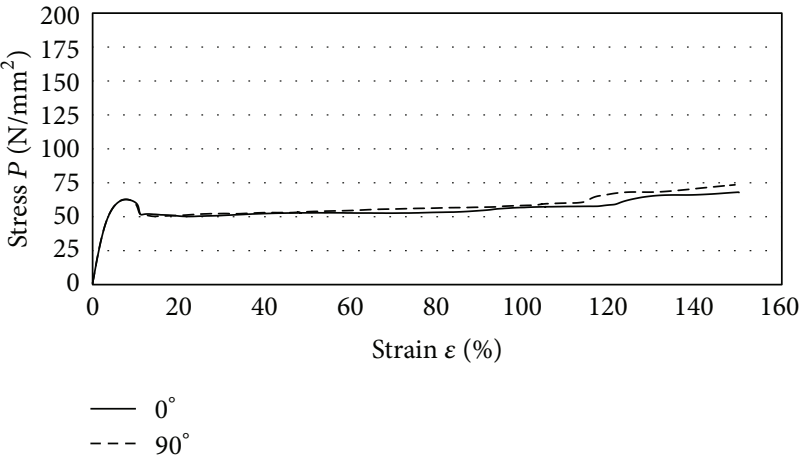

(a)

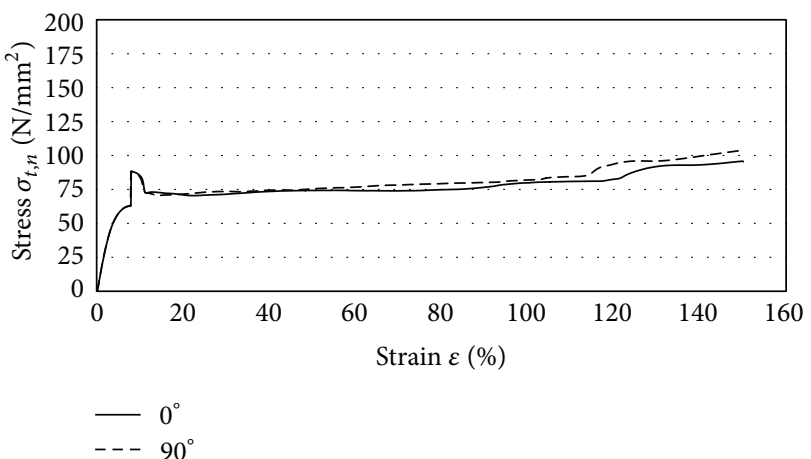

(b)

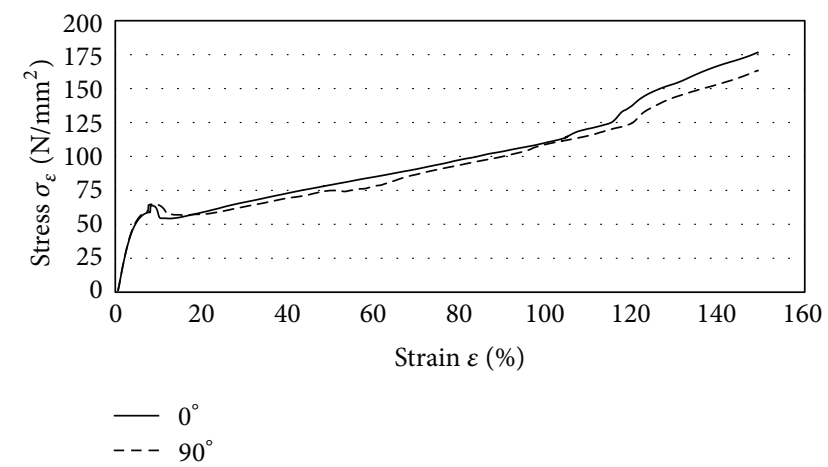

(c)

FIGURE 4: Stress-strain profiles for $\alpha=0^{\circ}$ and $\alpha=90^{\circ}$ of the extruded polycarbonate film: (a) nominal curve as per (4), (b) approximately real curve as per (7), and (c) strain-dependent curve as per (12).

4.1. The First Loading Phase: Variation of the Prestrain $\left(\varepsilon_{c}\right)$. Polycarbonate films with an initial thickness of $450 \mu \mathrm{m}$ are subjected to strains of $\varepsilon_{c}=50 \%, 100 \%$, and $150 \%$ on a tensile testing machine at room temperature. This results in the approximate real stress-strain profiles shown in Figure 5 according to (7) for $A_{3}=9 \mathrm{~mm}^{2}$. In line with DIN EN ISO 527-3 [13], five stress-strain profiles are measured and shown here. The high level of reproducibility is very pronounced.

\subsection{The Second Loading Phase: Variation of the Material} Direction $(\alpha)$. From the cold-formed polycarbonate films, material specimens are again taken at $\alpha=0^{\circ}, \alpha=45^{\circ}$, and $\alpha=90^{\circ}$, and tensile tests are performed to EN ISO 5273 [13]. As can be seen in Figure 6, all the test bars are in the region of the lateral contraction. $\alpha=0^{\circ}$ corresponds here to the direction of loading of the first loading phase and $\alpha=90^{\circ}$ transverse to the loading direction. For the specimens strained to $\varepsilon_{c}=50 \%$, it can be seen that stretching of the molecule chains has already occurred. These are stretched even further to $\varepsilon_{c}=100 \%$. For $\varepsilon_{c}=150 \%$, they slide past each other.

To allow a comparison with the results from the first loading and be able to evaluate the effect of hardening, it is necessary to know the real stress $\sigma_{t}$. Because the specimens were taken from the region of the lateral contraction, the lateral contraction is minimal in the second loading phase, so that, for the currently area $A_{t}^{*}$, the following assumption can be made for calculating the stress:

$$
A_{t}^{*}=A_{0}^{*}
$$

Here, $A_{0}^{*}$ is the initial area of the newly cut material specimens, which means that the real stress is approximately the same as the nominal stress

$$
\sigma_{t, n}=\frac{F}{A_{t}^{*}} \cong \frac{F}{A_{0}^{*}}=P .
$$

By comparing the stress-strain curves at $\alpha=0^{\circ}, 45^{\circ}$, and $90^{\circ}$ (Figure 7), the anisotropy of the physical properties can be analyzed by cold-forming. Because the stress-strain curves at $\alpha=0^{\circ}, 45^{\circ}$, and $90^{\circ}$ deviate significantly from one another, the anisotropy of the mechanical properties exists here. The strength is at its maximum for $\alpha=0^{\circ}$ and at its lowest for $\alpha=90^{\circ}$. The maximum nominal stress for $\alpha=0^{\circ}$ measured here is around $140 \mathrm{~N} / \mathrm{mm}^{2}$ for a pre-strain of $\varepsilon_{c}=$ $50 \%$ and $\varepsilon_{c}=100 \%$. This increases to $160 \mathrm{~N} / \mathrm{mm}^{2}$ at $\varepsilon_{c}=$ $150 \%$. During the first stress phase, only a maximum stress of $120 \mathrm{~N} / \mathrm{mm}^{2}$ is reached here for $\sigma_{t, n}$. This therefore means that a hardening occurs at $\alpha=0^{\circ}$. Through the cold-forming, the macromolecules orientate themselves in the tensile direction, so that the forces are borne by covalent bonds instead of the secondary valence forces. The most important result of this investigation is that the anisotropy in the polycarbonate is 


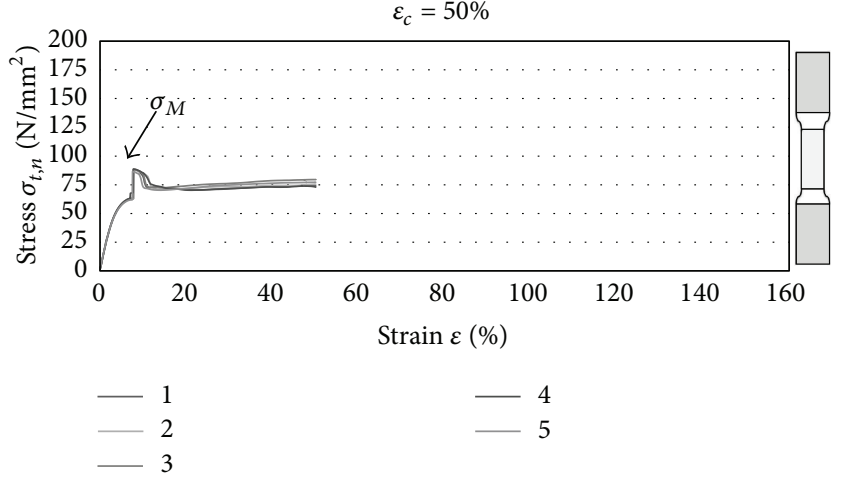

(a)

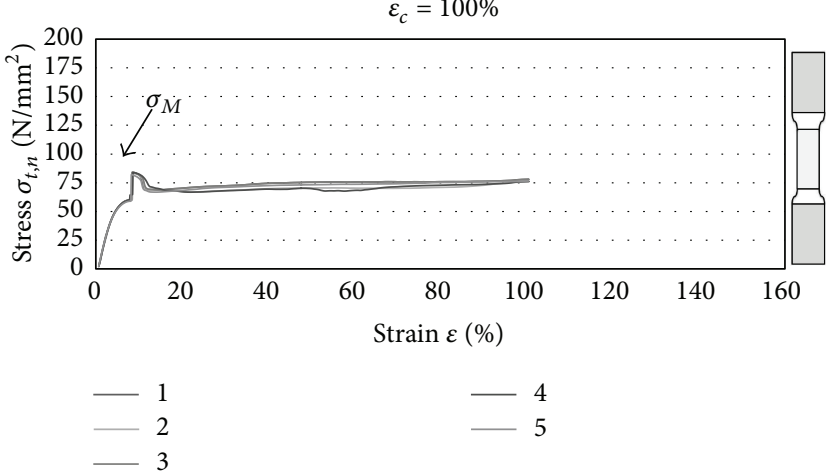

(b)

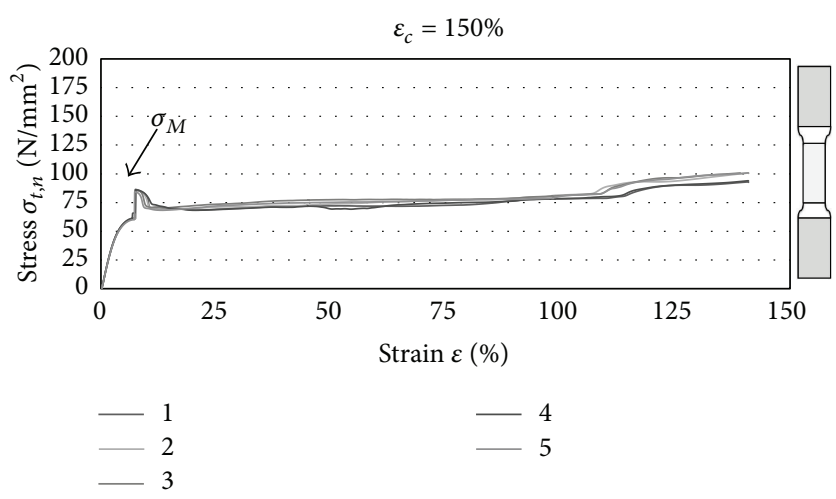

(c)

FiguRE 5: Stress-strain profiles for $\alpha=0^{\circ}$ and $\alpha=90^{\circ}$ of the extruded polycarbonate film: (a) nominal curve as per (4), (b) approximately real curve as per (7), and (c) strain-dependent curve as per (12).

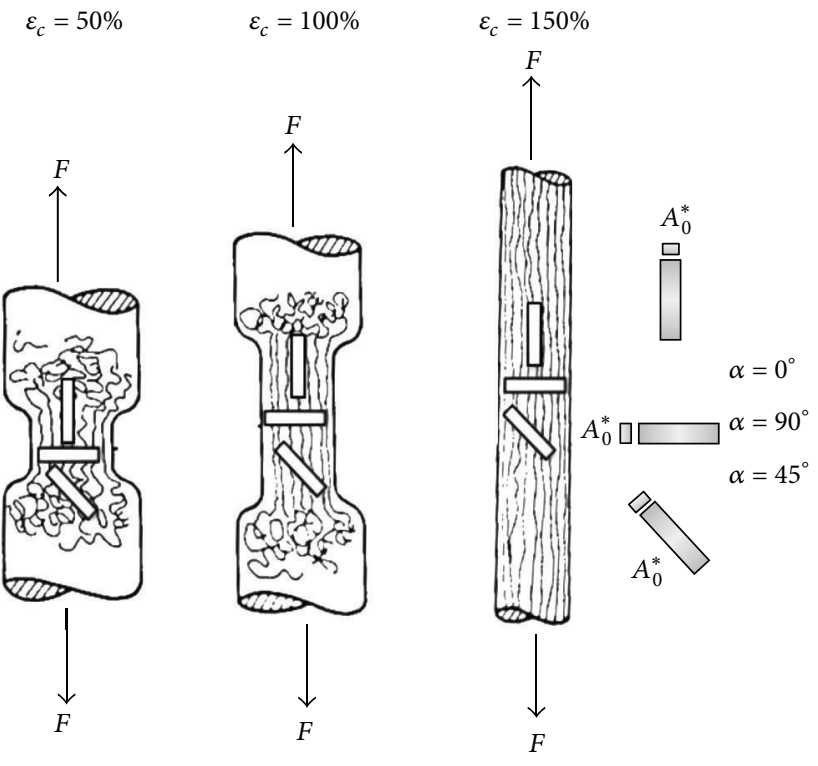

FIgURE 6: Variation of the material directions $\alpha=0^{\circ}, 45^{\circ}$, and $90^{\circ}$.

attained and that the influence of the material direction $\alpha$ is high.
In Figure 7, it is not recognizable at first glance whether the pre-strain $\varepsilon_{c}$ exerts an influence or not. For this reason, the stress-strain curves for the various pre-strain $\varepsilon_{c}$ are shown in Figure 8. Through the loading below the glass transition temperature, the molecule chains stretch up to a strain of $\varepsilon=120 \%$. At strains above $\varepsilon=120 \%$, the molecule chains slide past each other. According to [11], this results in a consolidation in the loading direction $\left(\alpha=0^{\circ}\right)$. This consolidation is also recognizable here.

\section{Anisotropic Data}

On the basis of the development of the anisotropies determined in the previous section, the mechanical data are also directionally dependent. There now follows a further evaluation of the maximum tensile strength, modulus of elasticity, and fractured strain. In line with EN ISO 527-3 [13], five tests were performed in each of the tensile tests. The diagrams in Figures 9, 10, and 11 show, for each test point, the mean value and the standard deviations of the five tests.

Through the differences in tensile strength $\sigma_{M}$, it is possible in Figure 9 to recognize the induced anisotropy of the tensile strength. Various stresses were calculated for the pre-strain. Here, it was found that the approximate real stress $\sigma_{t, n}$ is the closest to the real stress (the Cauchy stress) $\sigma_{t}$. Because the specimens were taken during the second loading 


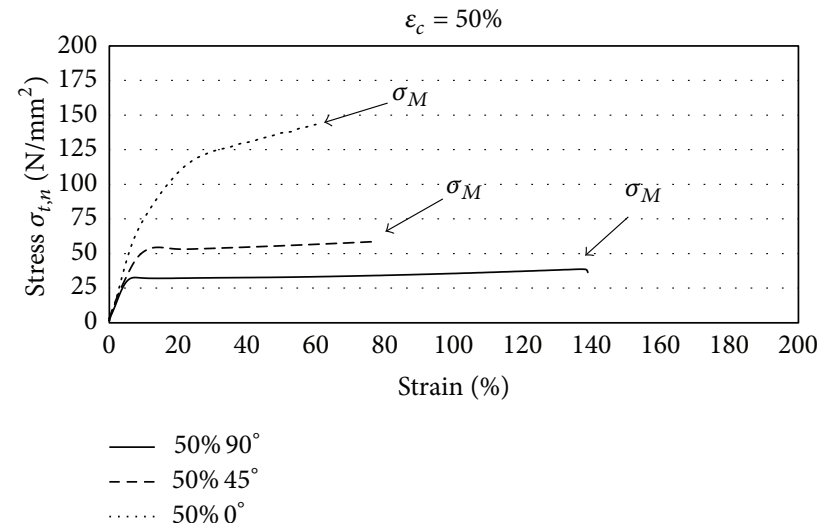

(a)

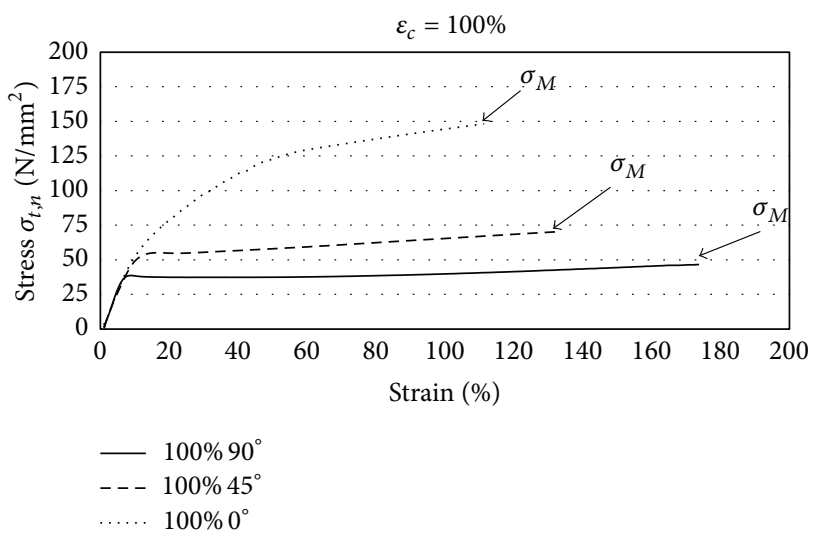

(b)

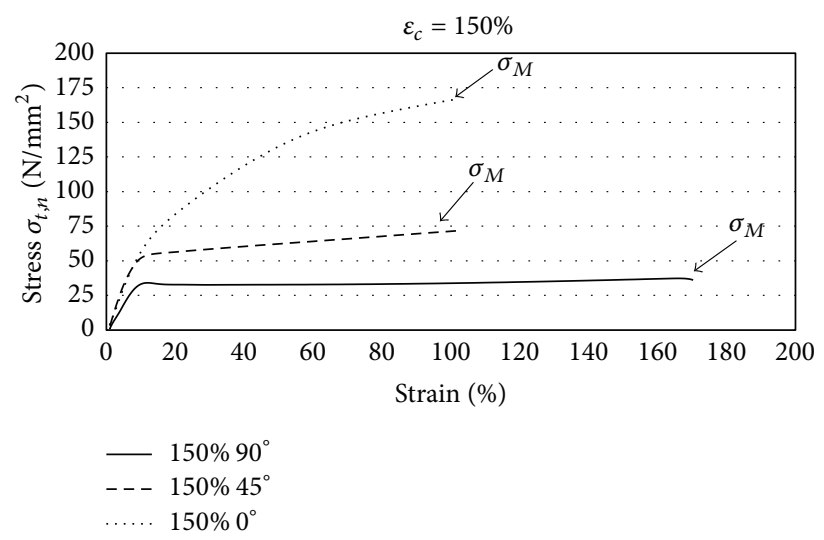

(c)

FiguRE 7: Stress-strain curves for the cold-formed polycarbonate films at $\alpha=0^{\circ}, 45^{\circ}$, and $90^{\circ}$.

phase from the area of the contracts laterally, it is assumed that $\sigma_{t, n}=P$.

The level of cold-forming at $\varepsilon_{c}=50 \%$ and $100 \%$ has no influence on the tensile strength. At a strain of $\varepsilon_{c}=150 \%$, on the other hand, a higher tensile strength is produced for $\alpha=$ $0^{\circ}$. This increase in strength declines in the $\alpha=90^{\circ}$ direction. For $\alpha=45^{\circ}$, there is a slight increase in tensile strength. On this occasion, however, it is not possible to state categorically whether a higher tensile strength occurs at an elongation of $\varepsilon_{c}=150 \%$ because of the high standard deviation.

The moduli of elasticity measured during elongation and the directionally dependent moduli of elasticity resulting from the cold-forming are compared in Figure 10. Loading below the glass transition temperature results in a decrease in the elasticity moduli. The elasticity modulus is independent of the pre-strain $\varepsilon_{c}$. This is due to the damage of the material caused by cold-forming. The elasticity moduli are determined according to DIN EN ISO 527-3 [13] in the range of 0.05\% and $0.25 \%$ strain. Since the contracts laterally do not occur until a strain of $\varepsilon=5 \%$, the elasticity modulus determined in the tensile test can be depicted here.

In the diagram in Figure 11, the fraction strain of the films removed in different directions is examined. Because of the different fraction strains, an anisotropy in the fracture behavior can be recognized. This rises for $\alpha=90^{\circ}$ with increasing load in $\alpha=0^{\circ}$. In contrast, for $\alpha=45^{\circ}$, the fraction strain declines with increasing stress because the molecules here are already pre-oriented. For $\alpha=0^{\circ}$-in other words in the direction of the load-the lowest fraction strain occurs, and this is independent of the pre-strain $\varepsilon_{c}$. The molecule chains here are so strongly oriented that no further orientation can occur, and fracture therefore becomes inevitable.

\section{Summary and Outlook}

Through cold-forming at room temperature, various kinds of anisotropy occur in polycarbonate films. In an analysis of the initial state, it was found that there is no anisotropy of the strength, stiffness, and fracture strain. The mechanical properties of the extruded polycarbonate film are isotropic in the $x$ - and $y$ - directions.

Through cold-forming, the maximum tensile strength $\sigma_{M}$ increases in the loading direction and decreases transverse to the loading direction. It can be seen clearly that the higher tensile strength is accompanied by lower fracture strain. The macromolecules are already so pre-oriented that fracture 


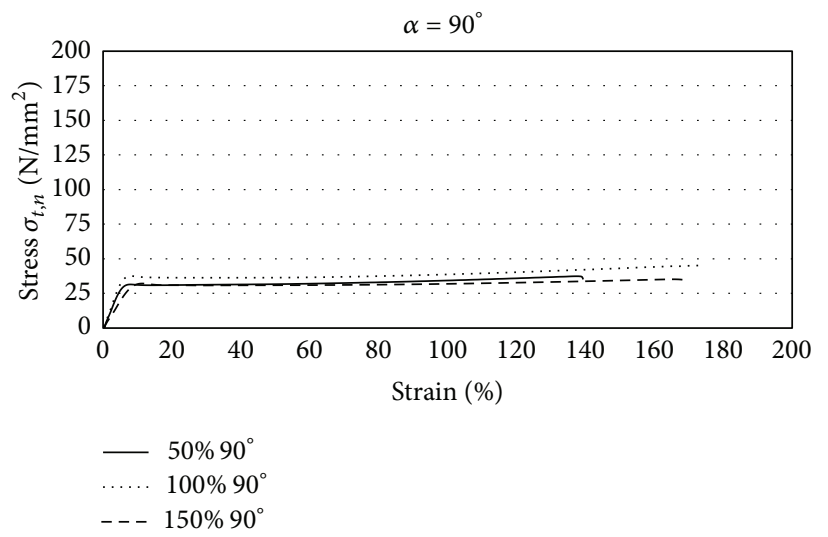

(a)

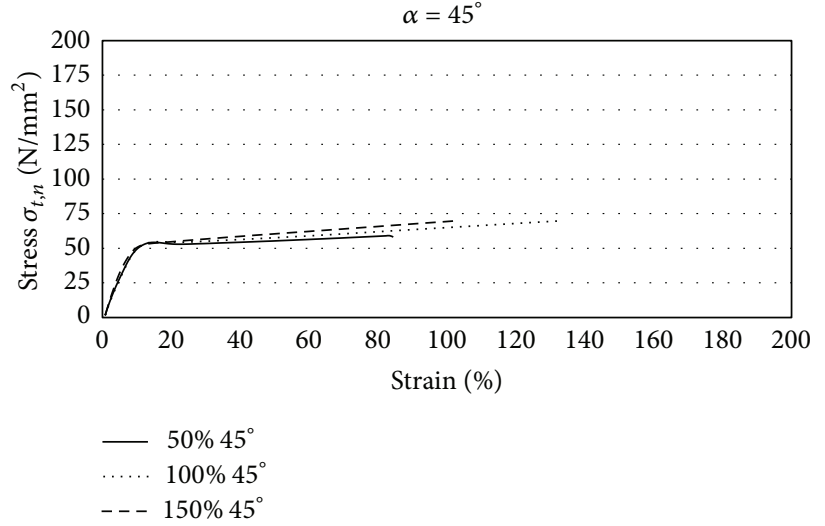

(b)

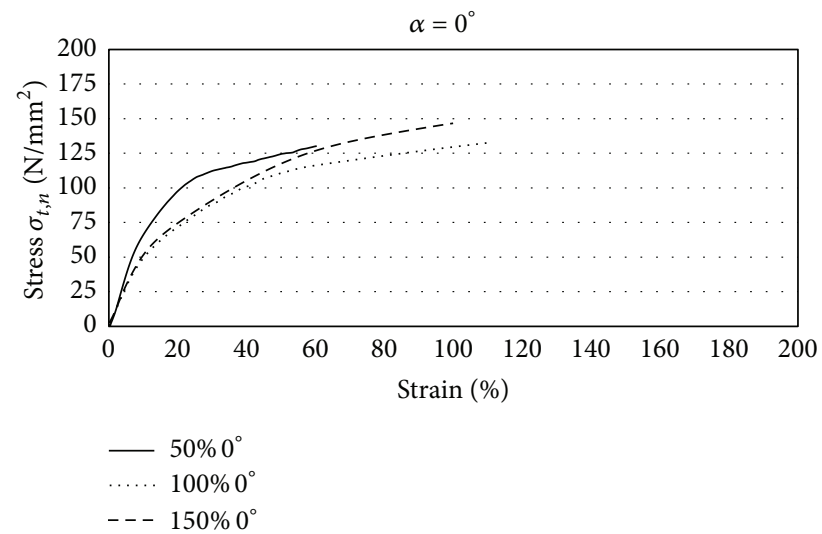

(c)

FIGURE 8: Stress-strain curves for the cold-formed polycarbonate films for the prestrains of $\varepsilon_{c}=50 \%, 100 \%$, and $150 \%$.

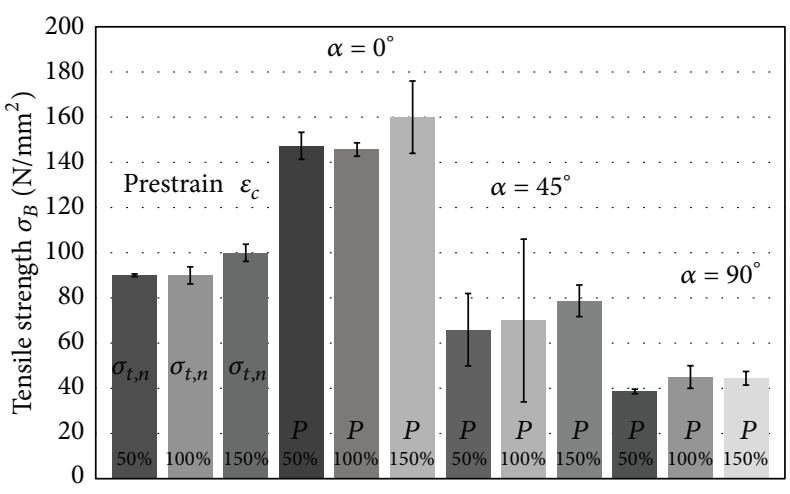

FIGURE 9: Comparison of the maximum tensile strengths and depiction of the strength anisotropy at $\alpha=0^{\circ}, 45^{\circ}$, and $90^{\circ}$ following the prestrains at $\varepsilon_{c}=50 \%, 100 \%$, and $150 \%$.

occurs. An examination of the elasticity moduli shows clearly that they decline considerably through cold-forming.

The main results of the experiments are as follows:

(1) the level of pre-strain $\varepsilon_{c}$ has little influence on the anisotropy;

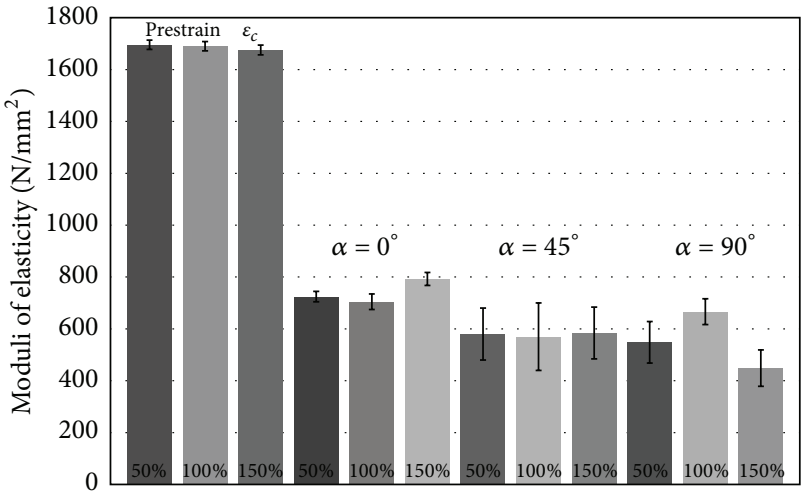

FIGURE 10: Comparison of the moduli of elasticity and depiction of the elasticity anisotropy at $\alpha=0^{\circ}, 45^{\circ}$, and $90^{\circ}$ as a result of the prestrain at $\varepsilon_{c}=50 \%, 100 \%$, and $150 \%$.

(2) the material direction $\alpha$ has a major influence on the anisotropy;

(3) cold-forming results in a hardening in the $0^{\circ}$ direction and a loss of hardening in the $90^{\circ}$ direction.

These findings on the deformation-induced anisotropy should be taken into account in followup studies concerned 


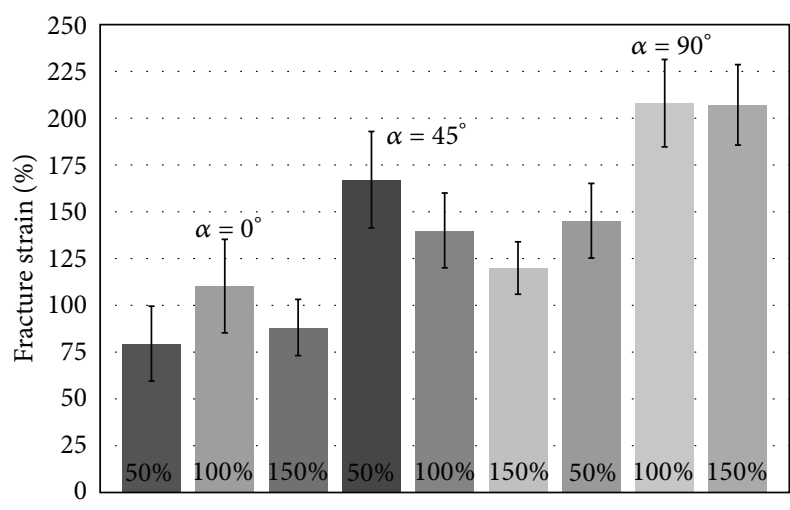

FIGURE 11: Comparison of the fracture strain and depiction of the anisotropy in the fracture behavior as a result of the prestrains $\varepsilon_{c}=$ $50 \%, 100 \%$, and $150 \%$.

with modeling the material behavior under complex stress and strain states as in [14-16]. The results described here are only a start. In subsequent tests, it must be established at which levels of strain the anisotropies begin to develop. In the tests described here, anisotropy tests were carried out at $\varepsilon_{c}=50 \%, 100 \%$, and $150 \%$. Here, the strain threshold ( $\left.\varepsilon=5 \%\right)$ has already been reached, and, up to $\varepsilon=120 \%$, only a system strain occurs. The local strain within the lateral contraction is constant. In subsequent tests, anisotropies should therefore be analyzed at comparatively low plastic deformations. Furthermore, tests with a larger database are needed to exclude any inhomogeneities in the material specimens and eliminate inaccuracies. In the results described here, only cold-forming was analyzed. For this reason, subsequent tests should also analyze anisotropies through hot-forming above the glass temperature to compare the results with those of the coldforming.

\section{Acknowledgments}

These investigations form part of the Collaborative Research Centre Transregio 30, sponsored by the German Research Foundation (DFG) as part of the project "Process-integrated production of functionally graded structures based on thermomechanically linked phenomena." The author would like to thank DFG for its support.

\section{References}

[1] B. Hornbogen and H. Warlimont, MetallkUnde: Aufbau und Eigenschaften von Metallen und Legierungen, Springer, New York, NY, USA, 4th edition, 2001.

[2] H.-Y. Oh and B. H. Kim, "The effect of rolling orientation on the brittle-ductile transition in polycarbonate fracture," Polymer Engineering and Science, vol. 26, no. 18, pp. 1290-1292, 1986.

[3] H. R. Schubach and B. Heise, "Structure and anisotropy in polycarbonate. I. Short range order of amorphous polycarbonate revealed by WAXS," Colloid \& Polymer Science, vol. 264, no. 4, pp. 335-342, 1986.

[4] L. Peetz, J. K. Krüger, and M. Pietralla, "Structure and anisotropy in polycarbonate III. Study of elastic and optical properties of oriented samples with the method of high resolution Brillouin spectroscopy," Colloid \& Polymer Science, vol. 265, no. 9, pp. 761773, 1987.

[5] H. Hofmeier, Eigenschaften von Folien aus Poly-[2. 2-Bis(4-Hydroxyphenyl)-Propan-Carbonat], Farbenfabrik Bayer AG, Werk Dormagen, Germany, 1962.

[6] F. Schutze-Gebhardt, Die Spannungs-Dehnungs-Charakteristik Orientierter Polycarbonatfäden, Bayer AG, Ingenieurbereich Angewandte Physik, Dormagen, Germany, 1980.

[7] G. W. Ehrenstein, Polymer-Werkstoffe: Struktur und Mechanisches Verhalten, Hanser, Ohio, USA, 1978.

[8] G. Menges, E. Haberstroh, W. Michaeli, and E. Schmachtenberg, Werkstoffkunde Kunststoffe, Hanser, Ohio, USA, 5th edition, 2002.

[9] G. Erhard, Konstruieren Mit Kunststoffen, vol. 10, Hanser, München, Germany, 4th edition, 2008.

[10] B. Heine, Einführung in die Polymertechnik, Expert, Malmsheim, Germany, 1998.

[11] M. Ashby and D. Jones, Engineering Materials 2: An Introduction to Microstructures, Processing and Design, vol. 39 of International Series on Materials Science and Technology, Pergamon press, 1994.

[12] H. Hencky, "Über die Form des Elastizitätsgesetzes bei ideal elastischen Stoffen," Zeitschrift Für Technische Physik, vol. 9, pp. 215-220, 1928.

[13] NORM DIN EN ISO 527-3, "Bestimmung der Zugeigenschaften," Prüfbedingungen für Folien und Tafeln, Teil 3, 2003.

[14] A. Shaban, R. Mahnken, L. Wilke, H. Potente, and H. Ridder, "Simulation of rate dependent plasticity for polymers with asymmetric effects," International Journal of Solids and Structures, vol. 44, no. 18-19, pp. 6148-6162, 2007.

[15] H. Potente, L. Wilke, H. Ridder, R. Mahnken, and A. Shaban, "Simulation of the residual stresses in the contour laser welding of thermoplastics," Polymer Engineering and Science, vol. 48, no. 4, pp. 767-773, 2008.

[16] R. Mahnken, A. Shaban, H. Potente, and L. Wilke, “Thermoviscoplastic modelling of asymmetric effects for polymers at large strains," International Journal of Solids and Structures, vol. 45, no. 17, pp. 4615-4628, 2008. 

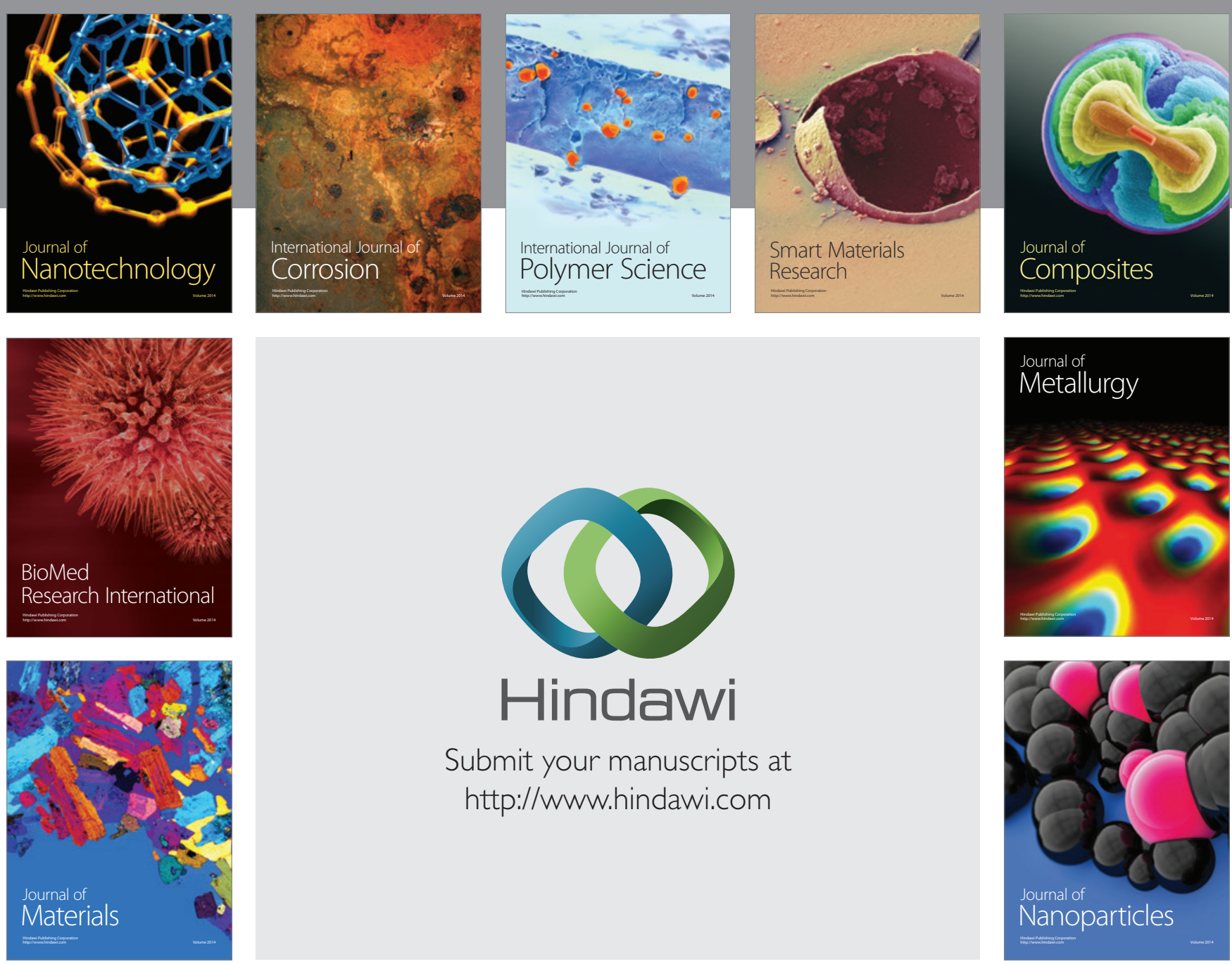

Submit your manuscripts at http://www.hindawi.com
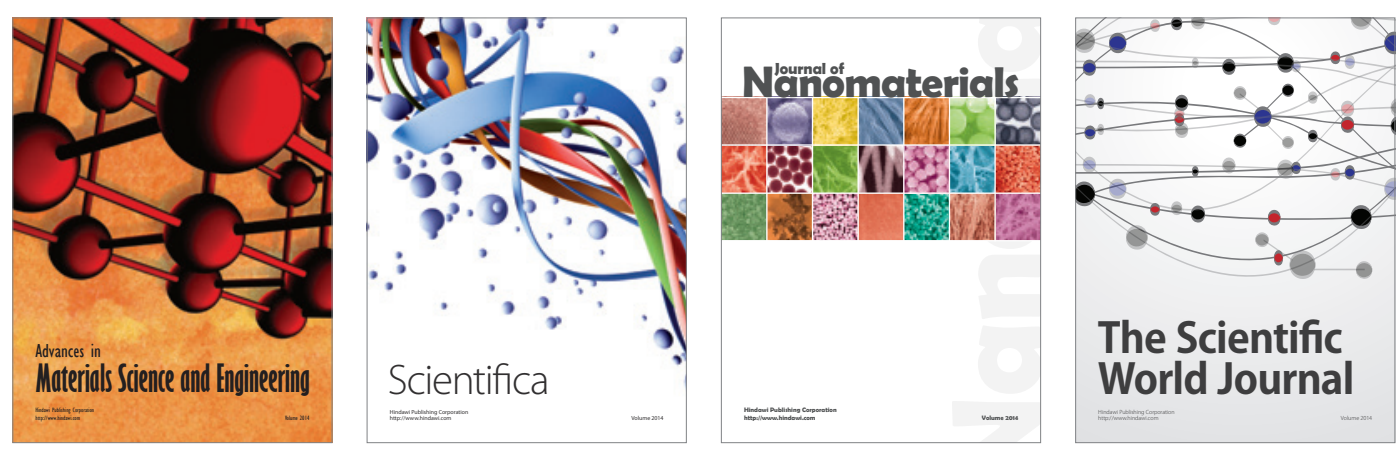

\section{The Scientific World Journal}
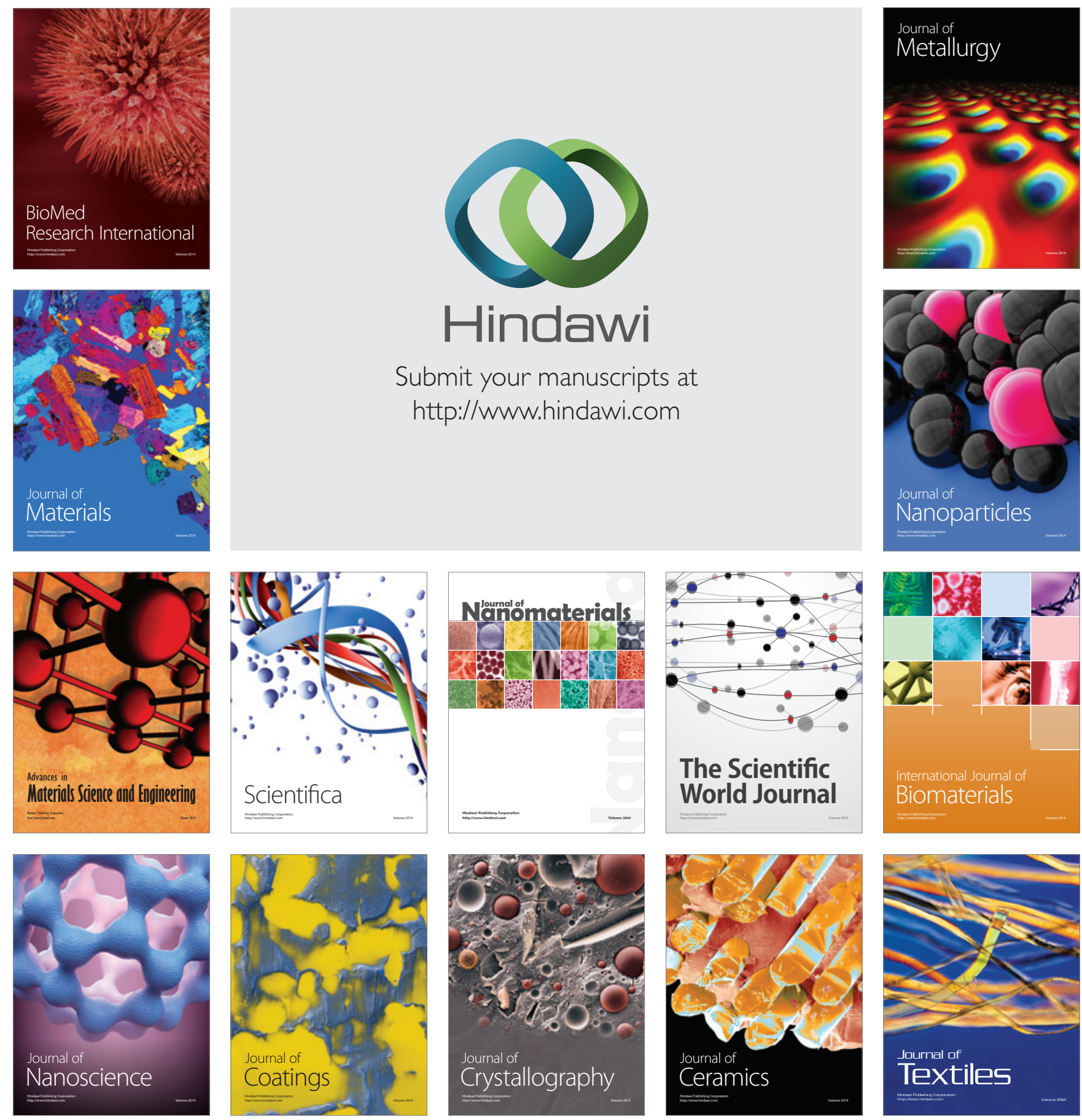